
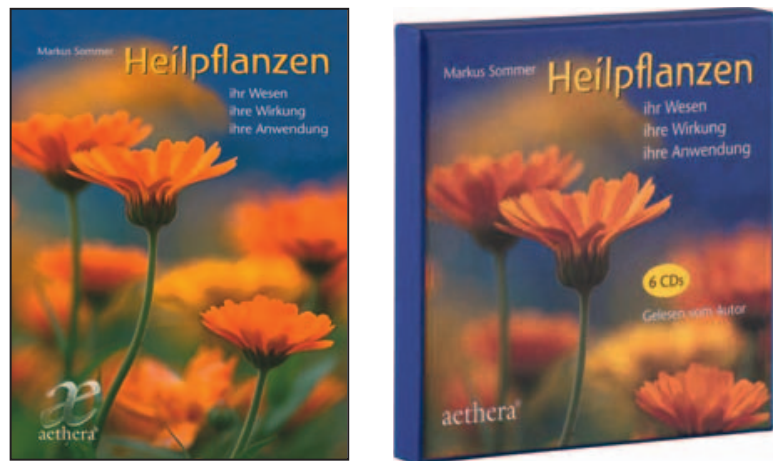

weisender und ganzheitlich bildhafter $\mathrm{Zu}$ gang zu ihrem Heilvermögen, den sich jeder Mensch bis zu einem gewissen Grad auch wieder selbst erarbeiten kann und durch den sich das Verhältnis vom Menschen zur Pflanzenwelt

Sommer, $M$.

Heilpflanzen

Ihr Wesen - ihre Wirkung ihre Anwendung

Stuttgart, Urachhaus, 2013, 432 S.,

28,90 EUR/ca. 37,90 CHF

ISBN 978-3-8251-8001-0

sowie

Heilpflanzen - 6 CDs

Hörbuch, gelesen vom Autor, Stuttgart, Urachhaus, 2013, 405 min, 24,90 EUR/ca. 39,90 CHF

ISBN 978-3-8251-8004-1

Das Buch und die gleichnamige $\mathrm{CD}$-Version sind unter dem schlichten Titel «Heilpflanzen» erschienen. Was verbirgt sich dahinter? Es ist ein tiefer Einblick in die Welt der heilenden Pflanzen, in die Markus Sommer den Leser oder Hörer mitnimmt. Zunächst schildert er die Pflanze im Jahreslauf, so wie wir sieim Beobachten und Miterleben kennenlernen können, und er regt durch die feine, bildhafte Sprache stark das eigene Miterleben und die innere Aktivität an. Es wird spürbar, dass der Kosmos der heilenden Pflanzen - in der Hand des kundigen Arztes - tief greifende Wirkungen entfalten kann. Neben der Vergangenheit der Volksheilkunde und dem homöopathischen Wissen eröffnet sich ein neuer, in die Zukunft

\section{grundlegend verändert.}

Schlichte Pflanzen werden da zum Teil besprochen, die wir mit unserem Fuss auf Weg oder Wiese oft achtlos zertreten, an denen Kinder eine Freude haben, die viele Erwachsene gar nicht mehr richtig wahrnehmen und die doch von erstaunlicher Heilkraft sein können, z.B. das Gänseblümchen (Bellis perennis). Man erfährt neben einer botanischen Einführung auch, wozu es in der Küche dienen kann. Eine einfach $\mathrm{zu}$ handhabende Herstellanleitung für ein aufhellendes Gänseblümchen-Gesichtswasser wird gegeben. Es erfolgen aber auch neueste wissenschaftliche Hinweise auf Substanzen, die diese Aufhellung von Sommersprossen oder Altersflecken bewirken. Dann folgen Angaben zu den homöopathischen und anthroposophischen Arzneimitteln, die aus Gänseblümchen hergestellt sind oder Gänseblümchen als einen Präparatbestandteil enthalten und derer man sich in der Selbstmedikation gut bedienen kann.

Mit über 40 Pflanzenporträts, die sich gegenüber der vor 2 Jahren erschienenen Erstauflage um einige Kapitel vermehrt haben, sind nun die wichtigsten Arzneipflanzen versammelt. Die ursprünglich im Lebensmagazin a tempo publizierten Heilpflanzendarstellungen hat Markus
Sommer, der in München seit Langem mit zwei Kollegen in einer anthroposophischen Gemeinschaftspraxis tätig ist, überarbeitet und um viele Anwendungshinweise ergänzt. Hier zeigt sich, in welch umfassend gründlicher und wesensgemässer Weise der Autor die Arzneimittellehre zu handhaben versteht.

Auch tief greifend wirkende Heilpflanzen mit Giftcharakter wie Schöllkraut, Eisenhut und Christrose sind unter den Porträts zu finden. Aus dem Tier- und Mineralreich haben sich als Licht bringende Stellvertreter die Biene und das Gold hereingeschlichen.

Auch bei den stark wirksamen Heilpflanzen ist relativ ausführlich das Anwendungsgebiet beschrieben, selbst wenn es um Malignome oder psychiatrische Krankheitszustände geht. Dabei nimmt es der Autor genau mit der Grenzziehung der Selbstmedikation. Das Buch ist somit für diejenigen, immer zahlreicher werdenden Menschen geschrieben, die sich nicht nur passiv einem ärztlichen Urteil unterwerfen möchten, sondern sich in Rücksprache und Beratung, wo es erforderlich ist, ein eigenes Urteil bilden und Eigenverantwortung für ihre Gesundheit übernehmen wollen. Als Wartezimmer-Lektüre werden die «Heilpflanzen» ein Zeichen setzen, dass der Arzt offen ist, auf die Gesichtspunkte des Patienten im Gespräch einzugehen, abgesehen davon, dass der Arzt selbst in seiner freien Zeit noch manchen Nutzen aus diesem fachlich und poetisch wunderbar geschriebenen Buch ziehen können wird.

Franziska Roemer, Bad Boll/Eckwälden 